\title{
Late Diagnosis of Breast Cancer and Associated Factors Among Women Attending Hawassa University Comprehensive and Specialized Hospital Southern Ethiopia
}

\author{
Mesay Yoseph ( $\nabla$ mesayoseph@yahoo.com ) \\ Hawassa University \\ Achamyelesh Gebresadik \\ Hawassa University \\ Akalewold Alemayehu \\ Hawassa University
}

\section{Research Article}

Keywords: Late breast cancer diagnosis, breast cancer, Hawassa University Specialized Hospital

Posted Date: September 24th, 2021

DOI: https://doi.org/10.21203/rs.3.rs-832493/v1

License: (c) (i) This work is licensed under a Creative Commons Attribution 4.0 International License.

Read Full License 


\section{Abstract}

Background; Breast cancer is a significant public health issue in sub-Saharan Africa and the second commonest cancer overall. In Ethiopia, most women present at the late-stage presentation. This is because Ethiopian government gives less attention, and is not well-studied as well. Therefore, it is important to assess delays in diagnosis and treating breast cancer that has been associated with a more advanced stage of the disease and a decrease in patient survival rates.

Objective: To assess the magnitude and associated factors for late diagnosis of breast cancer among women attending Hawassa University Comprehensive Specialized Hospital in Southern Ethiopia.

Methodology: A facility-based cross-sectional study was conducted from December to January 2019. Data were collected from 261 consecutively selected clients based on the arrival of their hospital visit by using a pretested structured questionnaire and checklist. Physicians performed physical examinations and diagnoses. Data was checked for completeness and consistency, and entered into epi data, then exported to SPSS for analysis. Descriptive, Bivariate, and multivariable logistic regression analyses were performed using SPSS Version 25 Statistical Software.

Results: The magnitude of late diagnosis of breast cancer was $86.3 \%$. The woman who had no initial advice for breast biopsy [AOR=5.1, 95\% ( $\mathrm{Cl}=1.4-18.9)$ ], not sharing the problem to others [AOR=4.7, 95\% $(\mathrm{Cl}=1.8-12.2)]$ and using traditional and faith healers as a first treatment choice $[\mathrm{AOR}=3.3,95 \%(\mathrm{Cl}=1.2$ 8.8)] were associated with late diagnosis of breast cancer.

Conclusions: The majority of women having breast cancer were diagnosed at a late stage. It needs attention to provide better options of the modern health service, and providing accessible initial advice for breast biopsy, and creating awareness about the benefit of sharing problems with family to improve the health of mothers by early diagnosing and managing the breast cancer.

\section{Background}

Breast cancer incidence is rapidly growing in both developed and developing regions [1]. It is typically detected either during a screening examination, before symptoms have developed, or after a woman notices a lump [2]. Delays in cancer care are common in low-income countries, resulting in greater morbidity, higher costs of care, a lower likelihood of survival, and disability from cancer [3].

Each year, more than 14 million people are diagnosed with cancer, the majority of whom live in low- and middle-income countries (LMICs) [4]. In 2015, 8.8 million died from cancer, representing one in six deaths globally [5]. Approximately two-thirds of worldwide cancer deaths are in developing countries, where case fatality rates are higher due to late-stage diagnoses, less accessible diagnostic and treatments services [4]. 
Breast cancer is the most common female malignancy in most African countries, being cancer with the first or second highest incidence and/or mortality [6]. According to the Global Action Plan for the Prevention and Control of Non-communicable Diseases (GLOBOCAN), breast cancer causes 269,000 deaths in Africa. The deaths number could have risen above this if there was complete cancer registration. The number of death from breast cancer in Africa is estimated to be double by the year 2050 [4]. In sub-Saharan Africa (SSA), breast cancer survival rates are poor, diagnosis of cancer at earlier stages could prevent deaths [7].

In Ethiopia, breast cancer is the first frequent cancer next is cervical cancer. It is estimated that about ten thousands Ethiopian women have breast cancer with thousands of more cases unreported as women living in rural areas often seek treatment from traditional healers before seeking help from the government health system $[6,8]$. The incidence of breast cancer in Ethiopia was $30.2 \%$, among these late diagnoses was $85 \%$ [9]. However, Ethiopia has an increasingly comprehensive set of breast cancer prevention, diagnosis, and treatment interventions available for women [10]. However, these services are limited to certain comprehensive tertiary hospital which are very far for the most residents. Moreover, these services are mostly ineffective, and have system-related barriers. It is further worsened by the women's attitudes, and lack of awareness of breast cancers symptoms also account for a slowed-down initiation of action [13].

The magnitude of late diagnosis of breast cancer, and its determinant factors are not well studied in the area. Therefore, conducting this study was found to be very important. This can be helpful for public health officials, clinicians, and health planners to do interventions to reduce the impacts of late diagnosis of breast cancer.

\section{Methods}

\section{Study setting and study population}

The study was carried out in Hawassa University Comprehensive Specialized Hospital, Sidama region. The study area is located $275 \mathrm{~km}$ south of Addis Ababa, the capital of Ethiopia. It is expected to serve more than 18 million people of the Sidama, Southern region and the surrounding Oromia zones. The hospital provides surgical and chemotherapy treatment service for breast cancer patients including the pathologic diagnostic services. The oncology unit of the hospital provides for more than 2000 clients per year. Among these, about 600 breast cancer were diagnosed in last year, 2018.

\section{Study design, and study population}

Facility-based cross-sectional study design with quantitative data was carried out in Hawassa University Comprehensive Specialized Hospital, Sidama Region, Ethiopia. The study population was all women who diagnosed for breast cancer and arrive consecutively from December to January, 2019. 


\section{Eligibility Criteria}

Inclusion criteria: All women diagnosed with breast cancer either newly diagnosed or on follow-up were included in the study.

Exclusion criteria: Those patients who had cancer from another site and disseminated to the breast, critically ill patient and patients with mental problem were excluded from study.

\section{Sample size and sampling procedures}

The sample size (n) was calculated by using the single population proportion formula. From the similar study from Tikur Ambessa Specialized Hospital, Addis Ababa, the proportion of late diagnosis of breast cancer ( $p$ ) was $88.89 \%$ [12]. 95\% Confidence interval (Cl) (1.96), 4\% margin of error (d), and adding $10 \%$ contingency was assumed.

$$
\mathrm{n}=\left(Z_{1-\alpha / 2}\right)^{2} \frac{P[1-P]}{d^{2}} \quad \mathrm{n}=\frac{(1.96)^{2}(0.89)(0.11)}{0.04^{2}}=236.91 \approx \mathbf{2 3 7}
$$

Final sample size was $(237+23.7)=260.7 \approx 261$

In this study, 261 women with breast cancer were selected consecutively based on their arrival to the hospital during the study period.

\section{Data collection tools, and procedures}

Data were collected by face-to-face interviews by using a pre-tested questionnaire. A clinical data of the patient like; stage of diagnosis, methods, treatment planned and type of diagnoses were collected by using a pre-tested checklist (from the medical records after physicians performed diagnoses). The questionnaire was developed by the investigators after reviewing different related literature. The questionnaire was first prepared in English, and then appropriately translated into the Amharic language. The component of the questionnaire was introductory, demographic information, socio- economic information, information on reasons for delay, patient's history on diagnostic procedures, patient's history on help seeking, health awareness and behavioral factors of the patients. The interviews were conducted in outpatient and inpatient departments of oncology unit in the hospital. Four pre-trained nurses collected data under the strict supervision of principal investigator.

\section{Data Analysis}


After data collection, each questionnaire was again visually checked for completeness, clarity, and accuracy. The data were coded and entered into EPI INFO version 7, exported into the SPSS version 25 Software. Descriptive, bivariate, and multivariable logistic regression analyses were performed. Selected variables that have a P-value of $\leq 0.2$ at the bivariate analysis were included in the multivariable logistic regression to control all possible confounding factors simultaneously. The goodness of fit was assessed by using the Hosmer and Lemeshow goodness test. Generally, a P-value $\leq 0.05$ was considered statistically significant.

\section{Operational definitions}

Late diagnosis; patients diagnosed with breast cancer stage III and stage IV on their first diagnosis in last six month [2].

Early diagnosis; patients diagnosed with breast cancer stage 0, Stage I andStage II

Cancer staging; is important in diagnosis in order to give appropriate management.

Breast cancer staging based on TNM classification, T stands for tumor size $\mathrm{N}$ for lymph node involvement depending on methods (2)

Patient delay: The period from a patient first becoming aware of symptoms until their first presentation to a health care provider (HCP). The duration of more than 60 days defined as "long patient delay" and 60 days or less defined as short patient delay" [15].

Alternative therapy: Complementary alternative therapy was defined as any therapy using methods and products not included in conventional modern medicine (traditional medicine, and traditional and religious practices [16].

\section{Results}

\section{Socio-demographic characteristics}

A total of 255 woman who diagnosed for breast cancer participated with a response rate of $97.70 \%$. Majority of the respondents 219 (85.9\%) were married and $183(71.8 \%)$ were urban dwellers. Fifty-nine (23.1\%) had no formal education. Nearly half 138 (54.1\%) of the participants were house wives and 94 (36.9\%) were employed (involved in government employee, private employee and private business). The average of parity ( \pm Standard Deviation) was $3.3( \pm 2.03)$, and majority $215(84.3 \%)$ of the women were multi-para. Sixty women (23.5\%) earned below average household monthly income, (below 1050 ETB) (Table 1).

Table 1: Socio demographic characters of woman who diagnosed for breast cancer among who visit oncology department in HUCRCH in Hawassa city, Southern Ethiopia, 2020. 


\begin{tabular}{|c|c|c|}
\hline Variables & Freq. & $(\%)$ \\
\hline \multicolumn{3}{|l|}{ Age } \\
\hline $25-29$ & 8 & (3.1) \\
\hline $30-34$ & 19 & $(7.5)$ \\
\hline $35-39$ & 55 & $(21.6)$ \\
\hline $40-44$ & 60 & $(23.5)$ \\
\hline $45-49$ & 45 & $(17.6)$ \\
\hline$\geq 50$ & 68 & $(26.7)$ \\
\hline \multicolumn{3}{|l|}{ Residence } \\
\hline Urban & 183 & (71.8) \\
\hline Rural & 72 & $(28.2)$ \\
\hline \multicolumn{3}{|l|}{ Marital status } \\
\hline Married & 219 & $(85.9)$ \\
\hline Divorced & 10 & (3.9) \\
\hline Separated & 9 & (3.5) \\
\hline Widowed & 14 & $(5.5)$ \\
\hline Single & 3 & $(1.2)$ \\
\hline \multicolumn{3}{|l|}{ Educational status } \\
\hline No formal education & 59 & $(23.1)$ \\
\hline Elementary & 84 & $(32.9)$ \\
\hline High school & 47 & $(18.4)$ \\
\hline College and above & 44 & $(17.3)$ \\
\hline First degree and above & 21 & $(8.2)$ \\
\hline \multicolumn{3}{|l|}{ Occupational status } \\
\hline House wife & 138 & $(54.1)$ \\
\hline Employed & 94 & $(36.9)$ \\
\hline Farmer & 14 & $(5.5)$ \\
\hline Daily laborer & 1 & $(0.4)$ \\
\hline Merchant & 8 & (3.1) \\
\hline
\end{tabular}




\begin{tabular}{|lll|}
\hline$\leq 1050$ ETB & 60 & $(23.5)$ \\
\hline 1051- 3342 ETB & 131 & $(51.4)$ \\
\hline$>3342$ ETB & 64 & $(25.1)$ \\
\hline Distance to oncology center & & \\
$\leq 6$ hours & 143 & $(56.1)$ \\
6 - 12 hours & 63 & $(24.7)$ \\
\hline More than days & 49 & $(19.2)$ \\
\hline
\end{tabular}

Employed: Government/ Civil servant + Non-Government employee,

Income according to WB $(1 \$, 1.9 \$, 3.15 \$$ /day $)$, while $(1 \$=34.95 E T B, 2020)$

\section{Patient's History and patient related determinant}

Out of 255 patients who attend health facilities, 253 (99.2\%) and 221 (86.7\%) were reported that they got consulted before being referred from hospital \& specialized clinic, respectively. Out of reported cases, 100 (39.2\%) on the right breast and 138 (54.1\%) were had on the left breast. Regarding the lymph node status, 119 (46.7\%) were documented and reported as Positive, on other hand 114 (44.7\%) also had one up to three lymph node involvement. Only 4 (1.6\%) of the participants had history of ever smoke cigarettes. More than half $142(55.7 \%)$ of the respondents were diagnosed breast cancer post-menopausal. Majority 214 (83.9\%) of the women breastfed their baby for more than two years and $174(68.2 \%)$ had history of contraceptive use.As figure shows below the majority of the study participants currently $97(38.0 \%)$ and $122(47.8 \%)$ were on stage III and VI, respectively. While, only $3(1.2 \%)$ were on stage II according to the TNM-Modified current stages of diagnosis (FIGO) (Figure 1).

\section{Patient's diagnostic pathway and reasons for delay}

Out of 255 women who had breast biopsy, 111 (43.5\%) infiltrating ductal carcinoma and 94 (36.9\%) were ductal carcinoma in situ by histological type. In addition to this, 102 (40.0\%) were well differentiated \& $108(42.4 \%)$ were moderately differentiated on their current grade. On other hand, 215 (84.3\%) who had surgical margin were not documented/reported. One hundred-two $(40.0 \%)$ had surgery and chemotherapy and hormonal therapy (Table 3). Regarding to delay; 135 (52.9\%) patient delay more than 60 days by their own reasons and 150 (58.8\%) referral delay, 163 (63.9\%) health care provider's (HCP) delay and 203 $(79.6 \%)$ were diagnostic results waiting time for more than 7 days. The major reasons for delay were claimed; 121 (55.5\%) were wait longer than 8 weeks between their presentation and final diagnosis, 152 $(69.1 \%)$ were report lack of cash money at that time, $40(18.2 \%)$ no health facilities or temporary relief 
from itself and $16(7.3 \%)$ perceived that the cancer had no cure. On other hand regarding to the health facility, 179 (81.4\%), $143(65.0 \%)$ and 124 (56.4\%) were complains that they delay due to the waiting time in the reception, waiting time to see a doctor and no appropriate physician, respectively (Table 2 ).

Table 2: Reasons for delay among the woman who diagnosed for breast cancer among who visit oncology department in HUCRCH in Hawassa city, Southern Ethiopia, 2020. $(n=220)$ 


\begin{tabular}{|c|c|c|}
\hline Variables & Freq. & $(\%)$ \\
\hline \multicolumn{3}{|l|}{ Above 8wks lag b/n presentation \& Dx } \\
\hline Yes & 121 & $(55.5)$ \\
\hline No & 97 & $(44.5)$ \\
\hline \multicolumn{3}{|l|}{ The reasons for late presentation } \\
\hline Lack of cash money at that time & 152 & $(69.1)$ \\
\hline No health facilities & 16 & $(7.3)$ \\
\hline Thinking that cancer was not be cured & 40 & $(18.2)$ \\
\hline Temporary relief by the lesion itself & 12 & $(5.5)$ \\
\hline \multicolumn{3}{|l|}{ Waiting time in the reception } \\
\hline Yes & 179 & $(81.4)$ \\
\hline No & 41 & $(18.6)$ \\
\hline \multicolumn{3}{|l|}{ Waiting time to see a doctor } \\
\hline Yes & 143 & $(65.0)$ \\
\hline No & 77 & $(35.0)$ \\
\hline \multicolumn{3}{|l|}{ Lack of appropriate attention } \\
\hline Yes & 124 & $(56.4)$ \\
\hline No & 96 & $(43.6)$ \\
\hline \multicolumn{3}{|l|}{ Being busy } \\
\hline Yes & 132 & $(60.0)$ \\
\hline No & 88 & $(40.0)$ \\
\hline \multicolumn{3}{|l|}{ Patient delay } \\
\hline$\leq 60$ days & 120 & $(47.1 \%)$ \\
\hline$>60$ days & 135 & $(52.9 \%)$ \\
\hline \multicolumn{3}{|l|}{ Health care provider's (HCP) delay } \\
\hline$\leq 7$ days & 92 & $(36.1 \%)$ \\
\hline$>7$ days & 163 & $(63.9 \%)$ \\
\hline \multicolumn{3}{|l|}{ Referral delay } \\
\hline$\leq 7$ days & 105 & $(41.2 \%)$ \\
\hline
\end{tabular}




\begin{tabular}{|lcc|}
$>7$ days & 150 & $(58.8 \%)$ \\
\hline Diagnostic waiting time & & \\
$\leq 7$ days & 63 & $(24.7 \%)$ \\
$>7$ days & 192 & $(75.3 \%)$ \\
\hline
\end{tabular}

\section{The Prevalence of Late Diagnosis of Breast Cancer}

The prevalence of late diagnosis of breast cancer among woman was 220 (86.3\%) [95\% Cl: 81.7-90.1], at visit oncology department at HUCRCH (Figure 2).

\section{Factors associated with late diagnosis of breast cancer}

In the bivariable logistic regression model, the analysis factors that had an association with late diagnosis of breast cancer were; advice for breast biopsy, residence, educational status, ever heard about mammography test, immediately share the problem to others, family history of cancer, menopausal status, and using traditional and faith healers as first choice. In the multivariate logistic regression analysis model; having no initial advice for breast biopsy, not sharing one's problem immediately to others, and using traditional healers or/and faith healers as first choice of treatments were significantly associated with late diagnosis of breast cancer.

Accordingly, the woman who had no initial advice for breast biopsy were 5 times more likely diagnosed at late stage $[A O R=5.1,95 \%(\mathrm{Cl}=1.4-18.9)]$ as compared with who had initial advised for breast biopsy. The women who did not share their problem immediately to others were 4.7 times more likely diagnosed at late stage with $[A O R=4.7,95 \%(C l=1.8-12.2)]$ as compared with who could share their problem with their family, husband and others. The study participants who use traditional and faith healers as first choice were also about three time more likely diagnosed at late stage $[A O R=3.3,95 \%(C l=1.2-8.8)]$ as compared with their counterparts (Table 3)

Table 3: Bivariable and multivariable logistic regression analysis late diagnosis of breast cancer among woman at HUCSH in Hawassa city, Southern Ethiopia, 2020. 


\section{Late diagnosis of $\mathrm{BCa}$}

Yes No

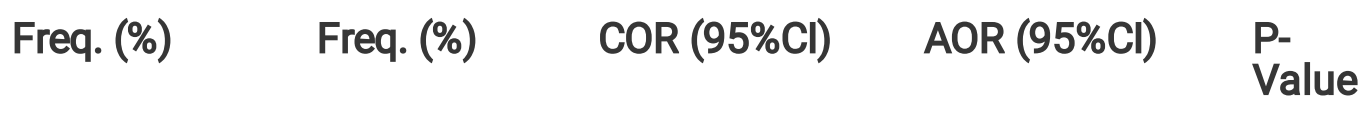

Advice for breast biopsy

$\begin{array}{llllllll}\text { No } & 8 & (57.1) & 6 & (42.9) & 1 & 1 & \\ \text { Yes } & 212 & (88.0) & 29 & (12.0) & \begin{array}{l}5.48(1.78, \\ 16.93)\end{array} & \begin{array}{l}5.13(1.39, \\ 18.90)\end{array} & 0.014^{*}\end{array}$

Residence

Urban

$153 \quad(83.6) \quad 30 \quad(16.4) \quad 1$

1

Rural

67

(93.1) $\quad 5$

(6.9) 2.63(0.98,

2.17(0.74,

$6.43)$

Educational status

$\begin{array}{lllllll}\text { No formal education } & 53 & (89.8) & 6 & (10.2) & \begin{array}{l}2.04(0.77, \\ 5.37)\end{array} & \begin{array}{l}1.42(0.38, \\ 5.29)\end{array}\end{array}$

$\begin{array}{lllllll}\text { Elementary } & 76 & (90.5) & 8 & (9.5) & \begin{array}{l}2.19(0.92, \\ 5.23)\end{array} & \begin{array}{l}1.44(0.40, \\ 5.21)\end{array}\end{array}$

$\begin{array}{lllllll}\text { High school and } & 91 & (81.3) & 21 & (18.8) & 1 & 1\end{array}$ above

Ever heard about mammography test

$\begin{array}{llllllll}\text { Yes } & 63 & (79.7) & 16 & (20.3) & 1 & 1 & \\ \text { No } & 157 & (89.2) & 19 & (10.8) & \begin{array}{l}2.10(1.02, \\ 4.34)\end{array} & \begin{array}{l}2.02(0.83, \\ 4.90)\end{array} & 0.122 \\ & & & & & & \end{array}$

Immediately share the problem to others

$\begin{array}{llllllll}\text { Yes } & 115 & (81.0) & 27 & (19.0) & 1 & 1 & \\ \text { No } & 105 & (92.9) & 8 & (7.1) & \begin{array}{l}3.08(1.34, \\ 7.08)\end{array} & \begin{array}{l}4.72(1.83, \\ 12.17)\end{array} & 0.001 \text { * } \\ & & & & & \end{array}$

Family history of cancer

$\begin{array}{llllllll}\text { Yes } & 18 & (75.0) & 6 & (25.0) & 1 & 1 & \\ \text { No } & 202 & (87.4) & 29 & (12.6) & \begin{array}{l}2.32(0.85, \\ 6.33)\end{array} & \begin{array}{l}2.28(0.74, \\ 7.02)\end{array} & 0.153 \\ & & & & & & \end{array}$

Menopausal status

\begin{tabular}{|c|c|c|c|c|c|c|c|}
\hline Pre-menopausal & 117 & (82.4) & 25 & $(17.6)$ & 1 & 1 & \\
\hline Post-menopausal & 103 & (91.2) & 10 & (8.8) & 2.20(1.01, & 1.75(0.63, & 0.285 \\
\hline
\end{tabular}


Using traditional and faith healers as first choice

\begin{tabular}{llllllll} 
No & 138 & $(82.6)$ & 29 & $(17.4)$ & 1 & 1 & \\
Yes & 82 & $(93.2)$ & 6 & $(6.8)$ & $\begin{array}{l}2.87(1.14, \\
7.21)\end{array}$ & $\begin{array}{l}3.29(1.23, \\
8.80)\end{array}$ & 0.017 * \\
& & & & & \\
\hline
\end{tabular}

NB; * P-value $<0.05$, was statistically significant, $1=$ Reference, $A O R=$ Adjusted Odds Ratio, COR= Crude Odds Ratio, $\mathrm{Cl}=$ Confidence Interval.

\section{Discussions}

This study primarily assessed the prevalence and associated factors for late diagnosis of breast cancer among women attending Hawassa University Comprehensive Specialized Hospital in Southern Ethiopia. Accordingly, recent study showed that the prevalence of late diagnosis of breast cancer among the woman who diagnosed for breast cancer was $86.3 \%$, [95\% Cl: 81.7-90.1]. This study result was consistent with the study reported from Addis Ababa, Ethiopia (88.89\%) [12]. The possible justification for the similarity of the findings is most likely due to both studies were conducted in relatively similar socioeconomic, health facilities and systems related factors. The recent finding was higher than in LMICs, between 30 and $80 \%$ are diagnosed in late stages [17, 18], 69\% Tanzania [19] and 60\% in Egypt [20]. This may be due to less education (in the study areas) on breast cancer especially who at higher risk of diagnosis delay, imparting adequate knowledge to its presenting signs and symptoms, also the necessity of regular self-breast examination. In addition to this majority of the rural community in the study areas still practice traditional and religious healers' alternatives before attending referral hospital. This also needs more attention on community mobilization, community-based screening programs and provide training for the traditional and religious healers.

This study finding showed that having no initial advice for breast biopsy or diagnosis is associated with late diagnosis of breast cancer. This finding is supported by the other study report from in Addis Ababa, Ethiopia [12]. This might be due to women who had no initial advice for breast biopsy diagnosis not aware on the consequence of breast cancer so they come lately to health institutions. Moreover, in Ethiopia, increasing the awareness on the breast cancer is not priority issues for the governments because government gives more priority for more very urgent health and health related issues. Furthermore, women with breast cancer have limited access to be consulted by the physicians because general hospitals are very distantly located.

Not early sharing the problem to others was also had significant association with late diagnosis of breast cancer. This finding is in line with the study conducted in Mexico [22], Columbia [23] and in Ethiopia [14]. In the culture of Ethiopia, women feel ashamed of sharing the reproductive health problem to their family members, their husband and others because breast is taken as sensitive part of the body to expose as equal as genitalia. This affects the early presentation of the women with breast cancer and contributes 
to lately diagnoses of the breast cancer. In addition to this, most of the time the women in the study area were economically dependent and they cannot afford the cost of modern treatments and diagnostic modalities unless they share their problems to their family members or husband.

This study finding revealed that using traditional and faith healers as first choice was associated with late diagnosis of breast cancer. This finding is supported by the similar study finding conducted in Cote d'Ivoire [24], Malaysia [25] and India [26]. In the study area, people who unable to afford the price of the modern medicine, modern radiologic diagnosis and other direct or indirect cost, are enforced to use traditional herbal medicines and faith healers as their first-choice because it is the easily available and affordable. In addition, biopsy, fine needle cytology or a core biopsy are performed in few large tertiary hospitals and specialized secondary level facilities which are not locally available and located much miles distant away. These all have a significant contribution for the late diagnosis of breast cancer.

\section{Recommendations and Conclusions}

This study has an implication to target better health practice and health seeking behavior at primary health care facilities level including health education to the women attending health facilities on screening, treatment, consequences of the late diagnosis of breast cancer. Moreover, health care system needs to provide training on modern health care system and the consequences of the late diagnosis of breast cancer for licensed traditional healers. Furthermore, health care providers need to provide consultation service on self-breast examination techniques, breast cancer screening, and informing them early symptoms can decrease the impact of the late diagnosis of the breast cancer. In addition, every woman should not be ashamed to share the reproductive health problems with their family, and health professionals also important to have successful treatment of the breast cancer.

In this study, we found a majority of the woman who diagnosed for breast cancer were diagnosed at late stage in my study. The woman who had no initial advice for breast biopsy, not sharing their problem immediately to others and using traditional medicines and faith healers as their first choice were associated with late diagnosis of breast cancer.

This was a hospital-based study. It lacks generalizability to the community at large. As this study was cross-sectional, the factors do not establish temporal relationship. Recall bias was tried to reduce but seems not completely avoided. Another limitation of recent study was small number of sample size. Future investigators should study with a large sample size with both quantitative and qualitative data inquiry.

\section{Abbreviations}




\begin{tabular}{ll} 
AOR & Adjusted Odds Ratio \\
\hline BCRF & Breast Cancer Research Foundation \\
\hline BSE & Breast Self-Examination \\
\hline CBE & Clinical Breast Examination \\
\hline CI & Confidence Interval \\
\hline COR & Crude Odds Ratio \\
\hline FIGO & International Federation of Gynecology and Obstetrics \\
\hline FMOH & Federal Ministry of Health \\
\hline Gyn & Gynecology \\
\hline HCPD & Health Care Provider's Delay \\
\hline IARC & International Agency for Cancer Research on Cancer \\
\hline IUCD & Intra Uterine Device \\
\hline MCH & Maternal and Childhood Health \\
\hline OPD & Outpatient Department \\
\hline OR & Odds Ratio \\
\hline SNNPR & Southern Nation Nationality and People Region \\
\hline TNM & Tumor, Lymph node and Metastasis \\
\hline UNICEF & United Nations Children's Fund \\
\hline WHO & World Health Organization \\
\hline CSA & Central Statistical Agency \\
\hline HUCSH & Hawassa University Comprehensive and Specialized Hospital \\
\hline
\end{tabular}

\section{Declarations}

\section{Ethics approval and consent to participate}

Ethical clearance was obtained from Hawassa University College of Medicine and Health sciences and conducted in accordance with the Declaration of Helsinki and was approved by an institutional review board or ethics committee. Support letter was obtained from the Hawassa University Comprehensive Specialized Hospital medical directory. All participants were informed about the purpose, risks, benefit and confidentiality issues related to the study. Participation was on voluntary basis and written informed consent (written informed consent was obtained from legally authorized representatives of respondent for those who cannot read and write). 


\section{Consent for publication}

Not applicable.

\section{Availability of data and materials}

The datasets used in this study are available from the corresponding author on reasonable request.

\section{Competing interests}

The authors declare that they have no conflict of interests.

\section{Funding}

Hawassa University provided fund for the study. The funder had no role in designing the study and conducting the analysis.

\section{Authors' contributions}

MY, AG, and AA participated in the conceptualization, formal analysis, investigation, methodology, supervision, visualization, writing-original draft, writing-review and editing, and approving the final draft. All authors read and approved the manuscript.

\section{Acknowledgments}

The authors would like to thank Hawassa University for providing fund for the study. The authors are grateful to all data collectors and study participants for their valuable contributions.

\section{References}

1. Freitas A., Gabrielly Q., Weller M. Patient delays and system delays in breast cancer treatment in developed and developing countries. Ciência \& Saúde Coletiva. 2015;20:3177-89.

2. Ben Fatma L., Belaid I., Said N., Gahbiche S., Hochlef M., et al. What could be the reasons of late diagnosis of breast cancer in Tunisia? La Tunisie medicale. 2018;96(10-11):665-71.

3. Brunet J., Saunders S., Gifford W., Thomas R., Hamilton R. An exploratory qualitative study of the meaning and value of a running/walking program for women after a diagnosis of breast cancer. Disability and rehabilitation. 2018;40(9):1041-8.

4. Ferlay J, Soerjomataram I, Ervik M, Dikshit R, Eser S, et al. Cancer Incidence and Mortality Worldwide IARC Cancer Base No. 11 [internet]. Lyon, France: International Agency for Research on Cancer, 2013.

5. WHO. Global health observatory. Geneva: World Health Organization; 2017

6. Hadgu E., Seifu D., Tigneh W., Bokretsion Y., Bekele A., et al. Breast cancer in Ethiopia: evidence for geographic difference in the distribution of molecular subtypes in Africa. BMC women's health. 2018;18(1):40-. 
7. Dickens C., Joffe M., Jacobson J., Venter F., Schüz J., et al. Stage at breast cancer diagnosis and distance from diagnostic hospital in a peri-urban setting: A South African public hospital case series of over 1000 women. Int J Cancer. 2014;1(135):2173-218.

8. Gemta E., Bekele A., Seifu D., Bekuretsion Y. Patterns of Breast Cancer Among Ethiopian Patients: Presentations and Histopathological Features. Journal of Cancer Science and Therapy. 2019;11:038-42.

9. Federal Ministry of Health Ethiopia, Disease Prevention and Control Directorate, National Cancer Control Plan, 2016-2020. 2015.

10. Biniyam T.D., Nikola C., Eugenia V.B., Alexandros T., Daniel R. Breast cancer care in northern Ethiopia: cross-sectional analysis. BMC Cancer 2019;19:393

11. Abate S., Yilma Z., Assefa M., Tigeneh W. Trends of Breast Cancer in Ethiopia. Int J Cancer Res Mol Mech 2016;2(1):1-5.

12. Bedada T., Teshale H., Hailu A., Mulugeta T. Prevalence and Factors Contributing to Late Diagnosis of Breast Cancer among Women Attending Tikur Anbessa Specialized Hospital, Oncology Unit, Addis Ababa, Ethiopia, 2017. J Integr Oncol 2018;7: 214.

13. Gebremedhin A., Shamebo M. Clinical profile of Ethiopian patients with breast cancer. East African Medical Journal. 2004;75(11): 640-3.

14. Gebremariam A., Addissie A., Worku A., Assefa M., Kantelhardt E.J., et al. Perspectives of patients, family members, and health care providers on late diagnosis of breast cancer in Ethiopia: A qualitative study. PloS one. 2019;14(8):e0220769.

15. Shieh S.-H., Hsieh V.C.-R., Liu S.-H., Chien C.-R., Lin C.-C., et al. Delayed time from first medical visit to diagnosis for breast cancer patients in Taiwan. Journal of the Formosan Medical Association. 2014;113(10):696-703.

16. Norsa'adah B., Rampal K.G., Rahmah M.A., Naing N.N., Biswal B.M. Diagnosis delay of breast cancer and its associated factors in Malaysian women. BMC Cancer. 2011;11(1):141.

17. Bastiaannet E., Charman J., Johannesen T.B., Schrodi S., Siesling S., et al. A European, Observational Study of Endocrine Therapy Administration in Patients With an Initial Diagnosis of Hormone Receptor-Positive Advanced Breast Cancer. Clinical breast cancer. 2018;18(4):e613-e9.

18. Iversen J.R., Amlie E., Hagen S., Harbitz T., Karesen R., et al. [Late diagnosis of advanced breast cancer-a challenge for health services]. Tidsskrift for den Norske laegeforening: tidsskrift for praktisk medicin, ny raekke. 2004;112(14):1821-4.

19. Yassin N.I.R., Omran S., El Houby E.M.F., Allam H. Machine learning techniques for breast cancer computer aided diagnosis using different image modalities: A systematic review. Computer methods and programs in biomedicine. 2018;156:25-45.

20. Harris E.E.R. Precision Medicine for Breast Cancer: The Paths to Truly Individualized Diagnosis and Treatment. International journal of breast cancer. 2018;2018:4809183.

21. McKenzie F., Zietsman A., Galukande M., Anele A., Adisa C., et al. Drivers of advanced stage at breast cancer diagnosis in the multicountry African breast cancer - disparities in outcomes (ABC-DO) study. 
Int J Cancer. 2018;142(8):1568-79.

22. Unger-Saldana K., Ventosa-Santaularia D., Miranda A., Verduzco-Bustos G. Barriers and Explanatory Mechanisms of Delays in the Patient and Diagnosis Intervals of Care for Breast Cancer in Mexico. The oncologist. 2018;23(4):440-53.

23. McElroy J.A., Proulx C.M., Johnson L., Heiden-Rootes K.M., Albright E.L., et al. Breaking bad news of a breast cancer diagnosis over the telephone: an emerging trend. Supportive care in cancer: official journal of the Multinational Association of Supportive Care in Cancer. 2019;27(3):943-50.

24. Toure M., Nguessan E., Bambara A.T., Kouassi Y.K., Dia J.M., et al. [Factors linked to late diagnosis in breast cancer in Sub-Saharan Africa: case of Cote d'Ivoire]. Gynecologie, obstetrique \& fertilite. 2013;41(12):696-700.

25. Hisham A.N., Yip C.H. Overview of breast cancer in Malaysian women: a problem with late diagnosis. Asian journal of surgery. 2004;27(2):130-3.

26. Sathwara J.A., Balasubramaniam G., Bobdey S.C., Jain A., Saoba S. Sociodemographic Factors and Late-stage Diagnosis of Breast Cancer in India: A Hospital-based Study. Indian journal of medical and paediatric oncology: official journal of Indian Society of Medical \& Paediatric Oncology. 2017;38(3):277-81.

\section{Figures}

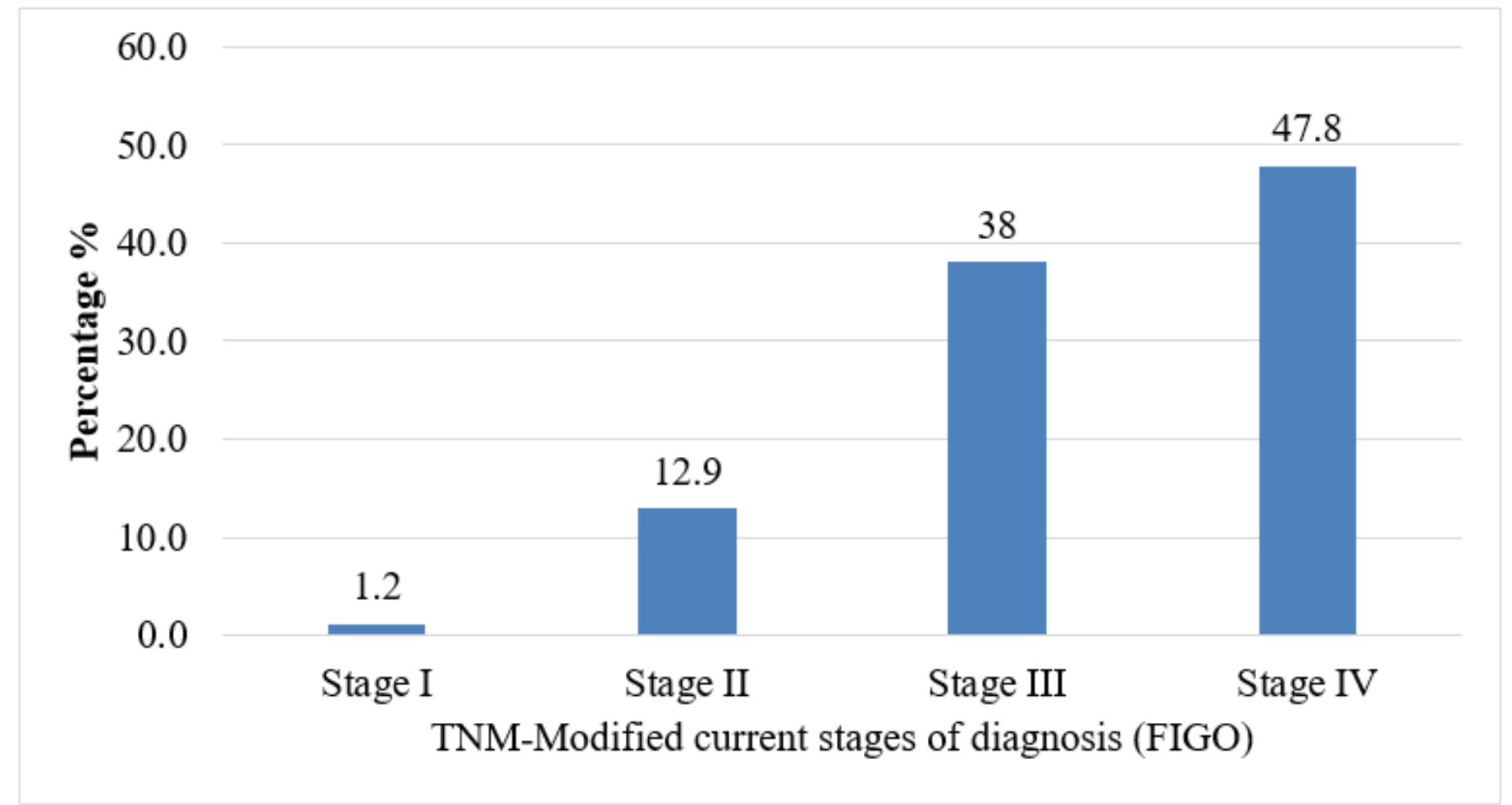

Figure 1 
TNM-Modified current stages of diagnosis of woman who diagnosed for breast cancer among who visit oncology department in HUCRCH in Hawassa city, Southern Ethiopia, 2020

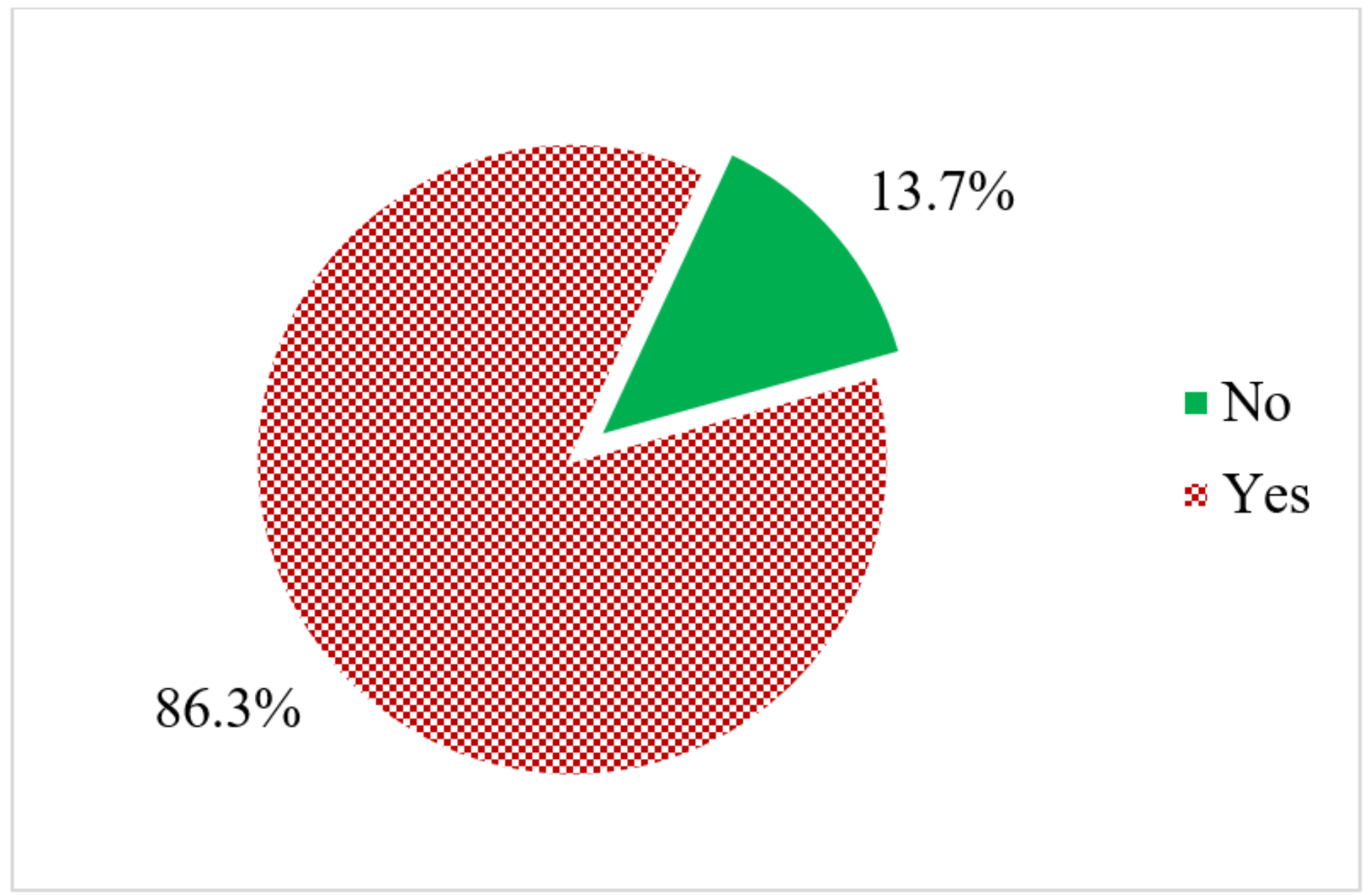

\section{Figure 2}

Late diagnosis of breast cancer among the woman who diagnosed for breast cancer among who visit oncology department in HUCRCH in Hawassa city, Southern Ethiopia, 2020. 